\title{
EXPERIMENTAL STUDY ON DYNAMIC ELASTIC MODUL AND R-WAVE VELOCITIES OF EPOXY MORTARS UNDER DIFFERENT TEMPERATURES
}

\author{
${ }^{\#}$ XIAOBIN LU*,**, XIULIN LI**, MENG LI** \\ * State Key Laboratory of Simulation and Regulation of Water Cycle in River Basin, \\ China Institute of Water Resources and Hydropower Research, 3 Yuyuantan South Rd., Beijing 10038, China \\ **Department of Structures and Materials, \\ China Institute of Water Resources and Hydropower Research, 3 Yuyuantan South Rd., Beijing 10038, China \\ \#E-mail: xluttnj@yahoo.com, xluttnj@qq.com
}

Submitted August 23, 2017; accepted December 4, 2017

Keywords: Epoxy mortar, Dynamic elastic modulus, R-wave velocity, SASW

This paper studies the variation of the dynamic elastic moduli and $R$-wave velocities of epoxy mortars with different binder to sand ratios subjected to a wide range of temperature change. It is found that, unlike concrete, the dynamic elastic moduli and $R$-wave velocities of epoxy mortars all decrease with increasing temperature, and a clear "knee" at around $30^{\circ} \mathrm{C}$ divides the curves into two approximately linear parts. Therefore, to guarantee a correct interpretation of the in-situ SASW results, the temperature-dependent $R$-wave velocities of epoxy mortars must be fully understood beforehand.

\section{INTRODUCTION}

Epoxy mortar is a commonly used surface-repairing material for concrete structures to protect concrete and rebars from erosion. Despite its wide usage, there still lacks a practical and effective approach in the field to evaluate the quality status of the material. The SASW (i.e., Spectral Analysis of Surface Wave) method was first put forward by Nazarian and Stoke in 1986 [1] to examine the R-wave propagation property of soil layers and pavements based on a seismic approach, and later it has been adopted in the inspection and safety evaluation of concrete structures $[2,3,4,5]$. The basic idea is to achieve the dispersion curve, i.e., R-wave velocity versus wave length, using phase difference cycles in the crosspower spectrum obtained from the frequency-domain analysis of the signals received by two transducers.

According to the stress wave propagation theory in infinite solid elastic media, the three-dimensional $\mathrm{P}$-wave velocity, S-wave velocity and $\mathrm{R}$-wave velocity can be expressed as follows:

$$
\begin{gathered}
V_{P 3}=\sqrt{\frac{E_{d}}{\rho} \frac{(1-v)}{(1+v)(1-2 v)}}, \\
V_{S}=\sqrt{\frac{E_{d}}{2 \rho(1+v)}}, \\
V_{R}=\frac{0.87+1.12 v}{1+v} V_{S},
\end{gathered}
$$

where $V_{P 3}, V_{S}$ and $V_{R}$ represent the three-dimensional $\mathrm{P}$-wave velocity, $\mathrm{S}$-wave velocity and $\mathrm{R}$-wave velocity, respectively; $E_{d}$ represents the dynamic elastic modulus, $\rho$ is the density and $v$ is the Poisson's ratio of the material. It can be seen from Equation 2 and Equation 3 that the $\mathrm{R}$-wave velocity is dependent on the dynamic elastic modulus $E_{d}$ of the material. $E_{d}$ is the ratio of stress to strain under vibratory conditions, and it is not only a key parameter for the dynamic analysis of structures, but a crucial durability indicator as well. For instance, ASTM C666 [6] uses the relative dynamic modulus of elasticity to evaluate the frost resistance of concrete. The dynamic resonance test is the most widely used method to obtain $E_{d}$ of concrete prisms in the laboratory [7].

For concrete, Neville [8] points out that under a very low stress/strain level in the dynamic resonance test of the specimen, the concrete essentially exhibits a linear elastic characteristic, and therefore the dynamic elastic modulus $E_{d}$ is approximately equal to the initial tangent elastic modulus $E_{t 0}$. Considering the fact that $E_{t 0}$ is closely related to the mechanical properties of concrete and $V_{R}$ is a function of $E_{d}$, thus in the field application, the measurement of $V_{R}$ through SASW tests can be used to assess the quality condition of the concrete within a certain depth beneath the surface of the structure in question.

Compared to concrete, epoxy mortar is more a viscoelastic material, which means that unlike concrete, its mechanical properties are mainly temperature-dependent. Therefore, to ensure an accurate assessment using the SASW method, the dynamic elastic moduli and R-wave velocities of epoxy mortars under different temperatures should be understood beforehand.

In this study, the impact-echo method is adopted to test $E_{d}$ of epoxy mortars bars under different temperatures based on the previous research done by the authors [9, $10]$, and is discussed below. 


\section{EXPERIMENTAL}

Impact-echo test

Figure 1 shows the impact-echo test setup for epoxy mortar bars. An elastic impact is applied with a $17 \mathrm{~mm}$ diameter steel spherical hammer at one end in the longitudinal direction of the bar, and an accelerometer is placed at the center of the opposite end of the bar to pick up the multiple reflection signals of stress waves. To ensure a free vibration, the specimens are laid horizontally on a sponge pad. In the test, each specimen is stricken four times. Although the epoxy mortar is a viscoelastic material, since the stress level induced by the steel ball impacting is very low, it is quite reasonable to assume that under such a small stress, the epoxy mortar still behaves in a near elastic manner, and thus Neville's point as mentioned above still stands.

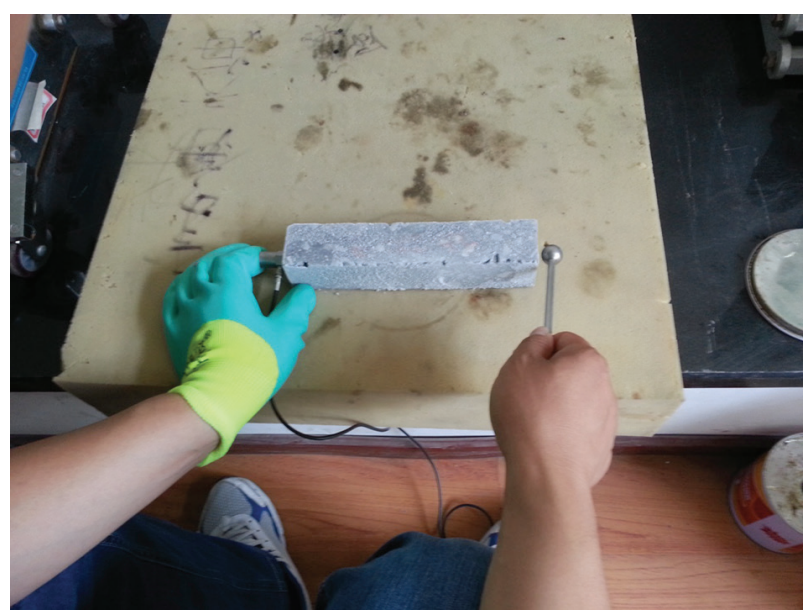

Figure 1. Impact-echo test setup for epoxy mortar bars.

The previous research done by the author [9, 10] shows that under an elastic impact, the predominant vibration mode along the longitudinal direction of a barshaped specimen with an aspect ratio $L / d$ no less than 2.0 conforms to the oscillating pattern caused by the one-dimensional $\mathrm{P}$-wave propagation along that direction, and thus the peak frequency on the response spectrum coincides with the frequency of that predominant vibration mode. Therefore, when applying the impactecho equation, it has been proven that the P-wave velocity obtained corresponds well with the theoretical one-dimensional P-wave velocity:

$$
V_{P 1}=2 \times L \times f,
$$

where $V_{P 1}$ is the one-dimensional $\mathrm{P}$-wave velocity, $L$ is the length of the bar-like specimen, and $f$ is the peak frequency on the response spectrum of spectral acceleration.

The theoretical one-dimensional P-wave propagation as in bar-like members in the elastic media can be expressed as follows:

$$
V_{P 1}=\sqrt{\frac{E_{d}}{\rho}},
$$

where $E_{d}$ represents the dynamic elastic modulus and $\rho$ is the density of the material.

In fact, Equation 4 and Equation 5 can be transformed into the equation stipulated in section 9.2 of ASTM C215 [7] to get dynamic elastic modulus using the longitudinal resonant frequency based on the impact resonance method.

In the impact-echo test of this study, the sampling rate and period were set to be $500 \mathrm{kHz}(2 \mu$ s interval) and $4096 \mu \mathrm{s}$, respectively, and the resulting amplitude response spectrum had a resolution of $0.122 \mathrm{kHz}$.

\section{Epoxy mortars and temperature chamber}

Three epoxy mortar mixtures with different binder to sand ratios, 1:6.3, 1:5.0 and 1:4.0, were made in the laboratory. The binder comprises epoxy resin and hardener with a resin to hardener ratio of 100:35, and the filler is quartz sand. It should be noted that the epoxy

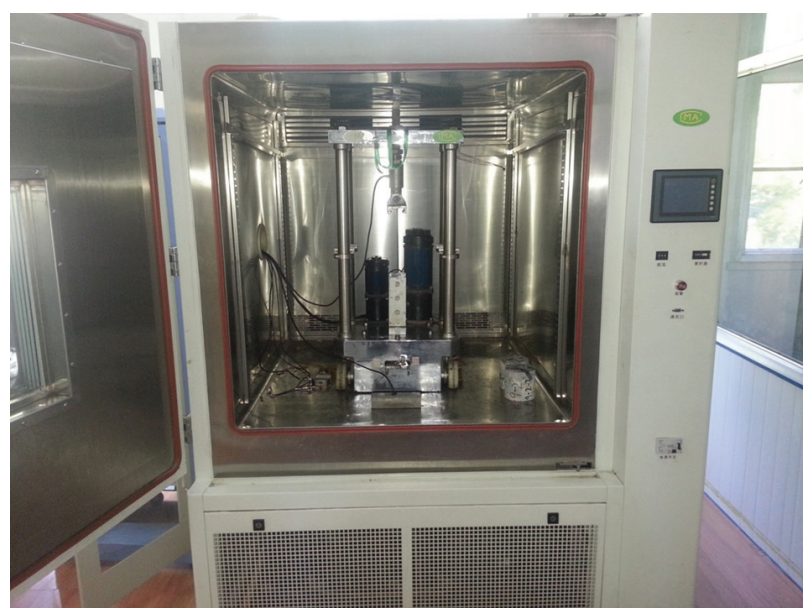

a) Temperature-simulating chamber

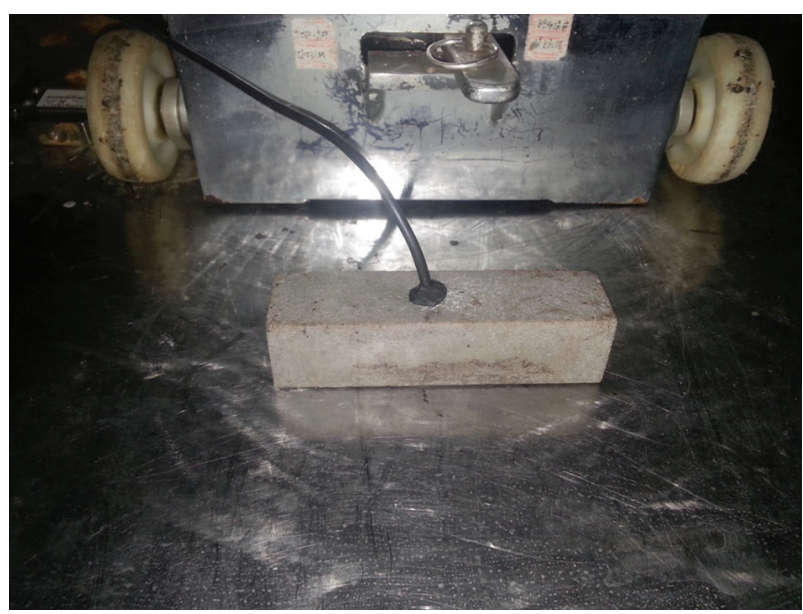

b) Control specimen inserted with sensor

Figure 2. Testing setup. 
mortar 1:6.3 is the same material used in the spillway discussed in the "Field Application" of this paper. After mixing, the epoxy mortar mixtures were cast into prismatic moulds with a dimension of $4 \times 4 \times 16 \mathrm{~cm}$, and after mould removal, the specimens were transferred to stay in a curing room with a constant temperature of $20^{\circ} \mathrm{C}$ for 3 whole weeks to fully develop their ultimate strengths.

At the age of 21 days, the epoxy mortar bars were put into a temperature-simulating chamber. A control specimen was selected and drilled right in the middle section to form a small hole where a temperature sensor could be inserted to monitor the internal temperature variation of the bar (see Figure 2). The impact-echo test was performed to all epoxy mortar bars at 11 temperatures from $-40^{\circ} \mathrm{C}$ to $60^{\circ} \mathrm{C}$ at an interval of $10^{\circ} \mathrm{C}$. The chamber was first set to cool down to $-40^{\circ} \mathrm{C}$ from the room temperature at a rate of $0.5^{\circ} \mathrm{C} \cdot \mathrm{min}^{-1}$, and after impactecho tests it was raised at the same rate to the next target temperature up to $60^{\circ} \mathrm{C}$. At each testing temperature, the reading of the sensor installed inside the control specimen was carefully examined to ensure the internal temperature of the specimen was maintained within $\pm 1^{\circ} \mathrm{C}$ around that testing temperature.

\section{RESULTS AND DISCUSSIONS}

At each testing temperature, the epoxy mortar bars were taken out of the temperature-simulating chamber one at a time, and the impact-echo test as shown in Figure 1 was performed as quickly as possible (normally

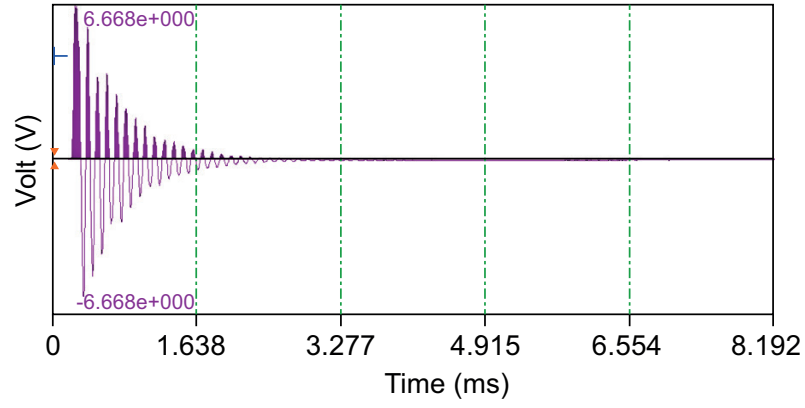

a)

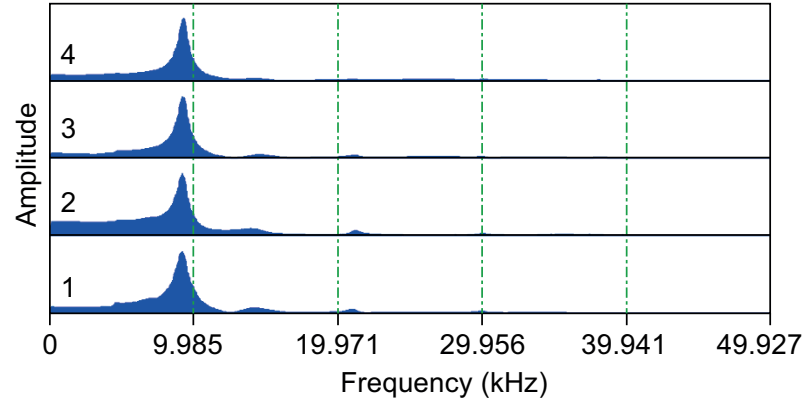

b)

Figure 3. Typical time domain signal (a) and stacked amplitude spectra (b) at $-40^{\circ} \mathrm{C}$ for epoxy mortar with binder-sand ratio 1:5.

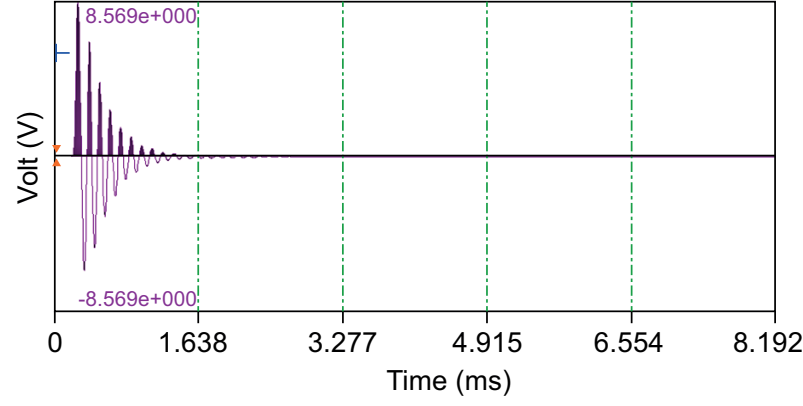

a)

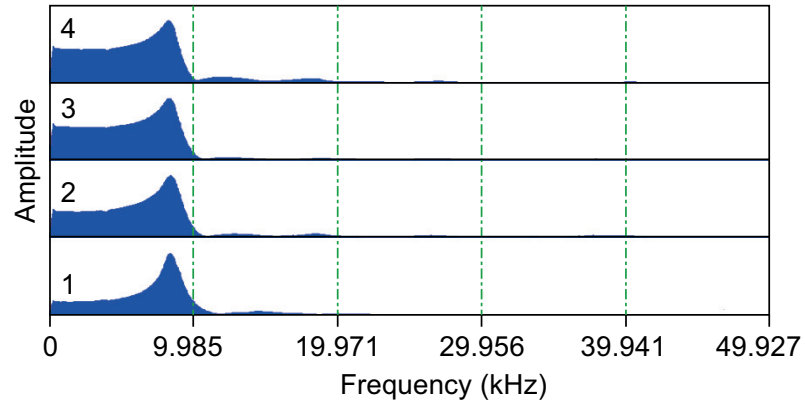

b)

Figure 4. Typical time domain signal (a) and stacked amplitude spectra (b) at $20^{\circ} \mathrm{C}$ for epoxy mortar with binder-sand ratio 1:5.

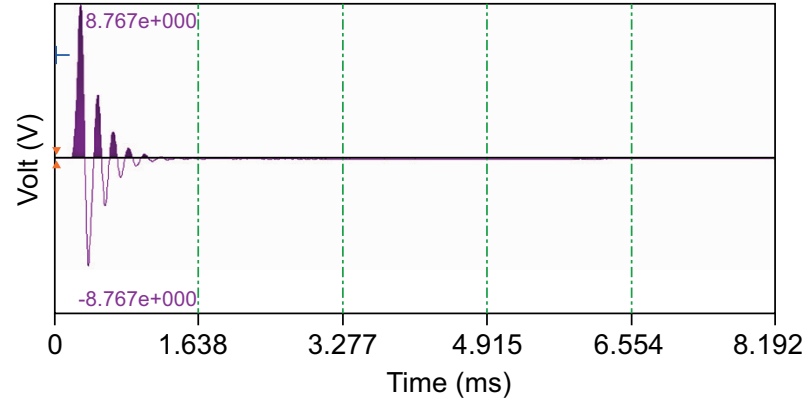

a)

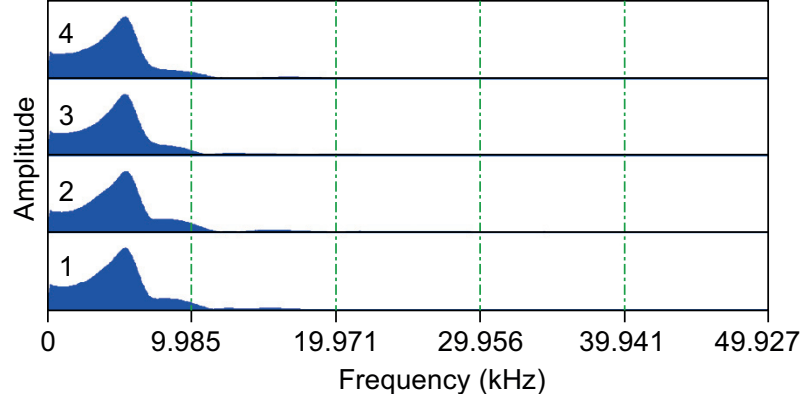

b)

Figure 5. Typical time domain signal (a) and stacked amplitude spectra (b) at $60^{\circ} \mathrm{C}$ for epoxy mortar with binder-sand ratio 1:5. 
within one minute) to maintain an insignificant temperature variation inside the specimen during the test. The one-dimensional P-wave velocity $V_{P 1}$ was obtained using Equation 4 based on the peak frequencies of the response spectra, and then the dynamic elastic modulus $E_{d}$ was achieved from Equation 5. The three-dimensional P-wave velocity $V_{P 3}$ and R-wave velocity $V_{R}$ were then calculated via Equations 1 through 3 . The Poisson's ratio of the epoxy mortar is taken as 0.3 , based on previous experimental studies of the author. Figures 3 through 5 show typical time domain signals received by the accelerometer and the corresponding amplitude spectra (4 test results vertically stacked) for a epoxy mortar bar with a binder to sand ratio of 1:5 under 6 selected testing temperatures of $-40,-20,0,20,40$ and $60^{\circ} \mathrm{C}$.

It can be seen that with the increase of temperature, the oscillations of the time domain signals diminish very noticeably. When the temperature is below $20^{\circ} \mathrm{C}$, the oscillating patterns of the epoxy mortar bars are still quite similar to those of $100 \times 100 \times 400 \mathrm{~mm}$ prismatic concrete specimens in the previous experimental study done by the author [9], but under high temperatures, the oscillation dies down much faster. Under low temperatures (especially below $20^{\circ} \mathrm{C}$ ), the epoxy mortar behaves dynamically rather like an elastic material.

In the frequency domain, it is quite obvious that only one peak frequency shows up on the amplitude spectra under all testing temperatures. This frequency corresponds to the frequency of the predominant vibration mode along the longitudinal direction of the epoxy mortar bar, and thus by applying Equation 4, the one-dimensional $\mathrm{P}$-wave velocity $V_{P 1}$ along the longitudinal direction of the bar can be achieved. It can also be seen from those spectra that the four results from the impact-echo test on each bar are very consistent, suggesting a reliable testing method.

With increasing temperature, the peak frequencies on the amplitude spectra gradually shift towards the left hand side, this shift becoming more evident when the temperature is above $20^{\circ} \mathrm{C}$. This trend of decreasing peak frequencies on the amplitude spectra bear some resemblance with that of the $100 \times 100 \times 400 \mathrm{~mm}$ prismatic concrete specimens subjected to rapid freezethaw cycles found in a previous research work done by the author [10].

The dynamic elastic moduli of 3 epoxy mortars calculated by Equation 5 are plotted against temperature in Figure 6. Generally, under the same temperature, $E_{d}$ of the epoxy mortar with a binder-sand ratio of 1:6.3 is a bit higher than that of epoxy mortar 1:5, but the epoxy mortar $1: 4$ is much lower than the above two. For instance, under the room temperature of $20^{\circ} \mathrm{C}$, the calculated $E_{d}$ are 13.6 GPa, 12.6 GPa and 9.6 GPa for the epoxy mortar with binder-sand ratio $1: 6.3,1: 5$ and 1:4, respectively, and with a roughly same sand content increase ratio of $4.0 \%, E_{d}$ is increased by $31.3 \%(9.6 \mathrm{GPa}$ to $12.6 \mathrm{GPa})$ and $8.3 \%(12.6 \mathrm{GPa}$ to $13.6 \mathrm{GPa})$. This indicates that with the increase of the sand content, $E_{d}$ of the epoxy mortar will increase, but the increase rate will gradually become slower. It should also be noted that under high temperatures (especially above $30^{\circ} \mathrm{C}$ ), the difference between $E_{d}$ of the three epoxy mortars narrows down, and for epoxy mortar 1:6.3 and 1:5, the two $E_{d}$ even become almost the same.

It is shown in Figure 6 that $E_{d}$ of the epoxy mortars decreases with the increase of temperature. Taking the epoxy mortar 1:5 for example, $E_{d}$ drops from $15.9 \mathrm{GPa}$ at $-40^{\circ} \mathrm{C}$ down to just $5.4 \mathrm{GPa}$ at $60^{\circ} \mathrm{C}$, a remarkable $66 \%$ loss. An obvious "knee" at around $30^{\circ} \mathrm{C}$ exists for all three epoxy mortars and divides the curves into two approximately linear parts. Below that temperature, the epoxy mortar behaves rather "elastically" as shown by the characteristic of the time-domain signals, and the decrease of $E_{d}$ is relatively smooth and linear with the temperature rise. However, above that temperature, the $E_{d}$ decrease becomes much sharper, although it still remains linear. This feature resembles the glass transition temperature $T_{g}$ of polymer materials such

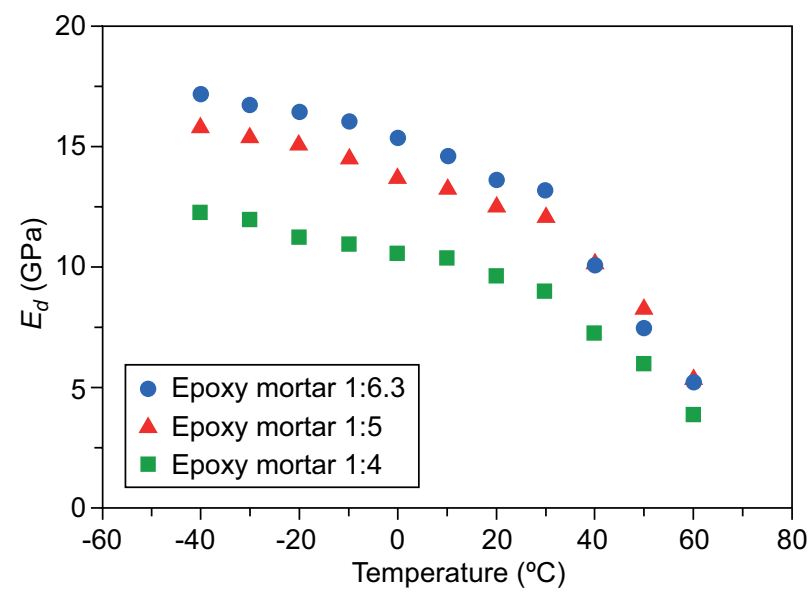

Figure 6. Temperature dependence of the dynamic elastic modulus $\mathrm{E}_{\mathrm{d}}$ for epoxy mortars with different binder-sand ratios.

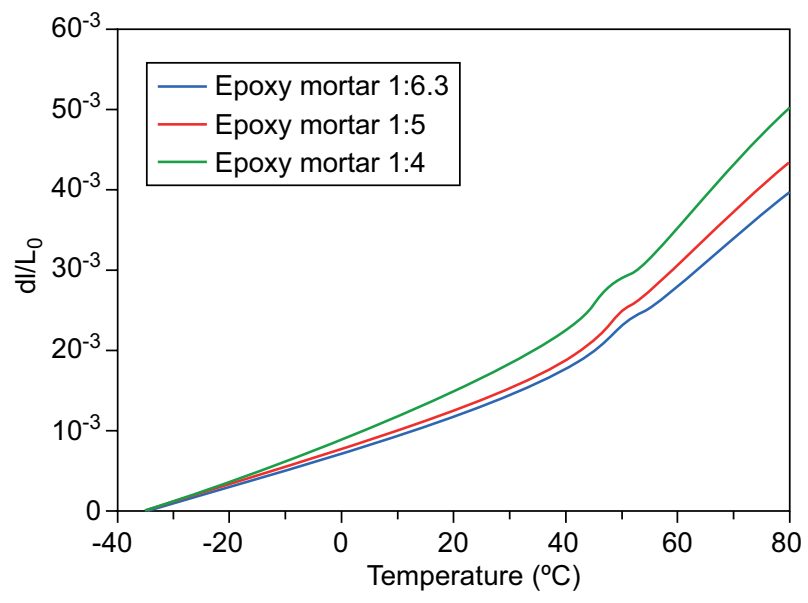

Figure 7. Thermal expansion tests to determine $T_{g}$ of epoxy mortars. 
as epoxy resin, which divides the material behaviour into elastomer-like and glass-like behaviour. Figure 7 shows the thermal expansion test results of three epoxy mortars, and the glass transition temperatures, which are defined by the kinks between two linear stages of each curve of expansion ratio versus temperature, are found to be approximately $45^{\circ} \mathrm{C}$. This indicates that the "knee" temperature on the $E_{d} \sim T$ curves is much lower than $T_{g}$.

In field applications, the R-wave velocity $V_{R}$ is often used with SASW method to evaluate the quality status of the material on the surface of a structure. The R-wave velocities of the three epoxy mortars are calculated via Equations 1 through 3 and are plotted against temperature in Figure 8. It can be seen that the $V_{R}$ variation versus temperature rise is similar to the $E_{d}$ change shown in Figure 6. Typical concrete has a $V_{R}$ of roughly $2500 \sim 2700 \mathrm{~m} \cdot \mathrm{s}^{-1}$ at all temperatures, but the $V_{R}$ of epoxy mortars is much lower due to their significantly lower $E_{d}$ values. For instance, the mortar 1:6.3 has a $V_{R}$ of $1725 \sim 1512 \mathrm{~m} \cdot \mathrm{s}^{-1}$ from $-40^{\circ} \mathrm{C}$ to $30^{\circ} \mathrm{C}$, which can still be considered as stable, considering the maximum difference of only $12.3 \%$ within that broad temperature range. However, in the narrow range of just $20^{\circ} \mathrm{C}$ from $40^{\circ} \mathrm{C}$ to $60^{\circ} \mathrm{C}, V_{R}$ exhibits a $28 \%$ sharp drop, decreasing from $1321 \mathrm{~m} \cdot \mathrm{s}^{-1}$ to $951 \mathrm{~m} \cdot \mathrm{s}^{-1}$. The situation is similar for the epoxy mortars with binder-sand ratios of 1:5 and 1:4.

In the field, the biggest concern for epoxy mortars should be the working temperature. Taking an extreme case of the epoxy mortar 1:6.3, if a $V_{R}$ standard at $-40^{\circ} \mathrm{C}$ as in the frigid winter $\left(1725 \mathrm{~m} \cdot \mathrm{s}^{-1}\right)$ is used to evaluate the condition of the epoxy mortar at $60^{\circ} \mathrm{C}$ as in the scorching summer $\left(951 \mathrm{~m} \cdot \mathrm{s}^{-1}\right)$, the final assessment may end up with a big misjudgment. Therefore, due to this apparent temperature-dependent characteristic, the $\mathrm{R}$-wave propagation properties of epoxy mortars under different temperatures need to be fully understood before conducting SASW tests. This study provides a convenient and effective method to serve for this purpose.

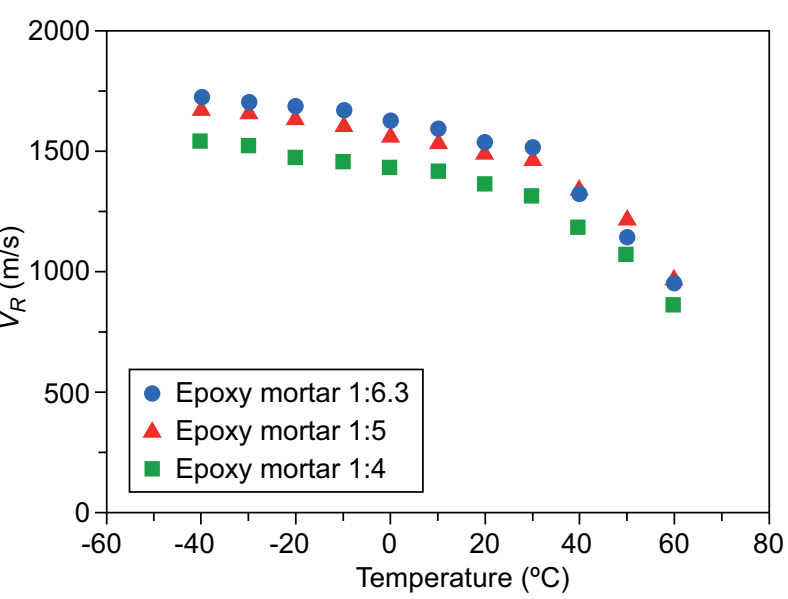

Figure 8. Temperature dependence of $\mathrm{V}_{\mathrm{R}}$ for epoxy mortars with different binder-sand ratios.
Field application

An inspection program was carried out to evaluate the current condition of the spillway of a concrete dam in southeastern China. Since the spillway mainly serves as a flood discharge facility, its surface condition is of great interest. The original concrete spillway was built in late 1950s, and after 60 years of operation, cracks began to develop and leakage occurred in the underneath powerhouse. To prevent this leakage, an epoxy mortar cover was applied on the spillway surface from October to November in 2011. The thickness of the cover was designed to be $2.0 \mathrm{~cm}$, and the materials and mix proportion used are the same with the epoxy mortar 1:6.3 discussed in the "Experimental Program" section of this paper. The SASW method was adopted as shown in Figure 9. The distance between two transducers was set to be $20 \mathrm{~cm}$, the sampling rate was $4 \mu$ s and the record size was 1024 .

A typical SASW analysis result obtained from a representative testing point is shown in Figures 10 and 11. During the field test, the surface temperature of the spillway was measured to be around $35^{\circ} \mathrm{C}$. Figure 10

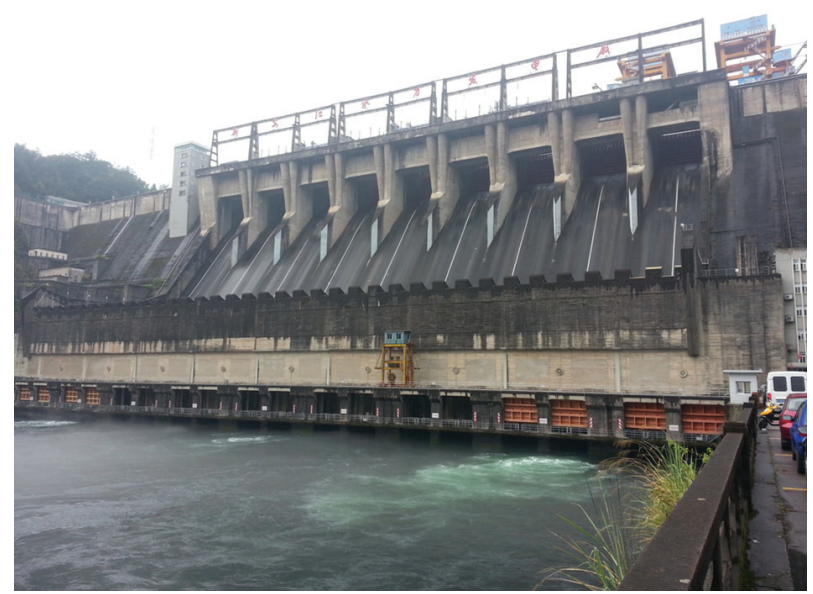

a)

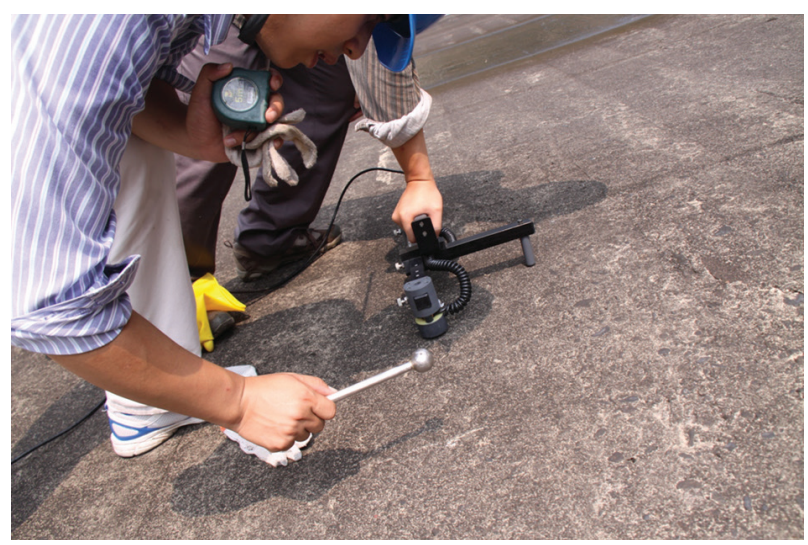

b)

Figure 9. Evaluation of surface condition of a concrete spillway using the SASW method. 
shows the cross power spectrum (i.e., phase difference cycles) of the time-domain signals of two transducers, and Figure 11 shows the dispersion curve (wavelength $\lambda_{R} \sim$ R-wave velocity $V_{R}$ ) obtained from the cross power spectrum in Figure 10 using the following equations:

$$
\begin{gathered}
V_{R}=2 \pi f d / \Delta \varphi, \\
\lambda_{R}=V_{R} / f,
\end{gathered}
$$

where $V_{R}$ is the R-wave velocity, $\lambda_{R}$ is the $\mathrm{R}$-wave length, $f$ is the frequencies along the phase cycles in Figure 10, $\Delta \varphi$ is the phase difference (in radians) corresponding to $f$, and $d$ is the distance between the two transducers.

The cross power spectrum in Figure 10 shows two clear phase difference cycles from about $6 \mathrm{kHz}$ to $22 \mathrm{kHz}$. Despite some noise at the high-frequency side, it can still be seen from the cross power spectrum that a phase discontinuity occurs at roughly $25 \mathrm{kHz}$, which can be attributed to the multiple P-wave reflections at the interface between the epoxy mortar and concrete [4]. Since the underlying concrete is acoustically stiffer, the classical impact-echo equation is not valid. To estimate the thickness of the epoxy mortar cover, the following equation can be used $[11,12]$ :

$$
T=V_{P} / 4 f,
$$

where $T$ is the thickness of the epoxy mortar cover, $V_{P}$ is the apparent $\mathrm{P}$-wave velocity in the epoxy mortar cover, and $f$ is the frequency associated with the multiple reflections between the interface and spillway surface. $V_{P}$ can be approximated as $0.96 V_{P 3}$ [13]. Since the epoxy mortar used in field is the same with the above-mentioned epoxy mortar 1:6.3, the cover thickness $T$ is calculated through Equation 8 to be about $3.0 \mathrm{~cm}$.

Due to the low signal coherence and noise interruption at high frequencies, the minimum valid wave length on the dispersion curve is only about $6 \mathrm{~cm}$, and the corresponding $V_{R}$ is roughly $1500 \mathrm{~m} \cdot \mathrm{s}^{-1}$. Adopting the commonly used half-wave length interpretation, this implies that the average $V_{R}$ for the material within a depth of $3.0 \mathrm{~cm}$ below the spillway surface is about $1500 \mathrm{~m} \cdot \mathrm{s}^{-1}$,

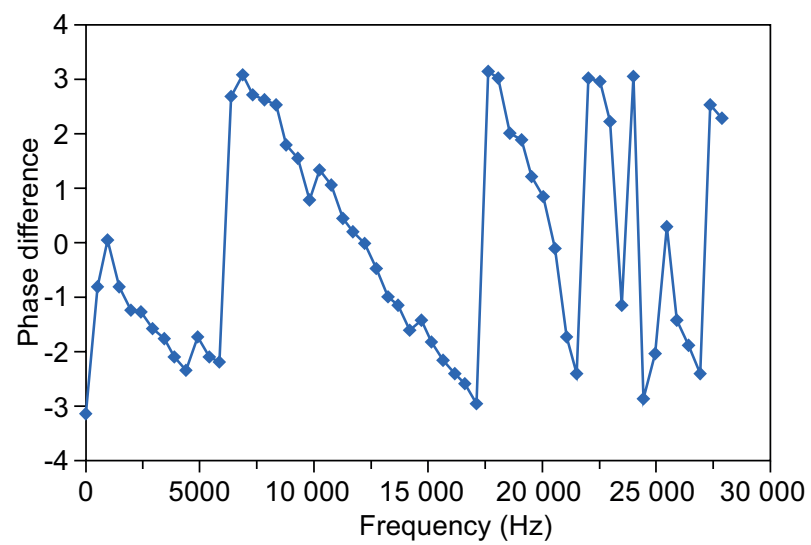

Figure 10. Time-domain signals with corresponding average coherence function and cross power spectrum. which is quite close to the estimated $V_{R}$ of $1420 \mathrm{~m} \cdot \mathrm{s}^{-1}$ of the epoxy mortar $1: 6.3$ at $35^{\circ} \mathrm{C}$. With the increase of the wave length $\lambda_{R}, V_{R}$ gradually goes up, and it reaches about $2500 \mathrm{~m} \cdot \mathrm{s}^{-1}$ at $\lambda_{R}=0.4 \mathrm{~m}$, which indicates the sound concrete base underneath the epoxy mortar cover.

Based on the SASW result, the thickness of the epoxy mortar cover satisfies the design requirement, and the dispersion curve shows that $V_{R}$ of the epoxy mortar has not undergone any significant deterioration in $E_{d}$. Core samples on the site tend to support this conclusion.

\section{CONCLUSIONS}

Based on impact-echo tests on epoxy mortar bars under different temperatures and in-situ SASW tests, the following conclusions can be drawn:

- With increasing temperature, the predominant frequencies on the response spectra of epoxy mortar bars move to the left hand side on the frequency axis; this phenomenon is quite similar to the concrete suffering from durability deterioration when subjected to rapid freeze-thaw cycles.

- As expected, under the same temperature, the dynamic elastic modulus of the epoxy mortar with a higher sand content is generally higher than that with a lower sand content; however, the increase rate of $E_{d}$ slows down considerably when the sand content exceeds a certain amount (for the materials used in this study, that threshold seems to be near a binder-sand ratio of $1: 5)$.

- The dynamic elastic moduli of epoxy mortars decrease with increasing temperature, and the temperature dependence consists essentially of two approximately linear parts. There is a clear "knee" at about $30^{\circ} \mathrm{C}$ for all three mortars with different sand contents. Below that temperature, the change of $E_{d}$ is smooth, but once that temperature is reached, $E_{d}$ of epoxy mortar undergoes a relatively big slump. This knee temperature on the $E_{d} \sim T$ curves is much lower than the glass transition temperature obtained from regular thermal expansion tests.

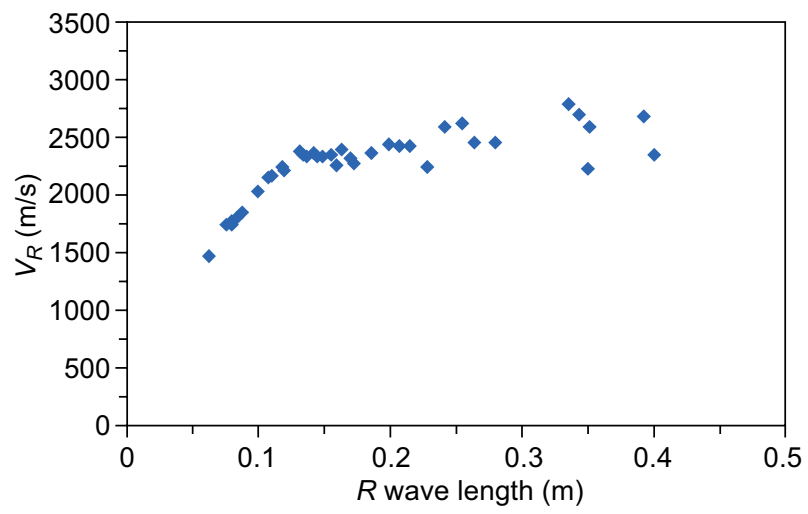

Figure 11. Dispersion curve from the cross power spectrum in Figure 10. 
- The R-wave velocities of epoxy mortars are significantly lower than that of concrete. The variation of $\mathrm{R}$-wave velocities of epoxy mortars with temperature has the same feature with that of dynamic elastic moduli, and there is also a sharper drop in $V_{R}$ when the temperature is over $30^{\circ} \mathrm{C}$.

- Due to the temperature-sensitive nature of epoxy mortars, to ensure a correct interpretation of SASW results, it is of great importance to first investigate their R-wave propagation properties under different temperatures.

\section{Acknowledgements}

The study is supported by the National "973” Plansponsored project "Structural Optimization Theory and New Structures for High RCC Dams" (project No.: 2013CB035903).

\section{REFERENCES}

1. Nazarian S., Stoke II K.H. (1986). In-situ determination of elastic moduli of pavements systems by spectral analysis of surface waves method (Theoretical aspects), Research report number 437-2. US Department of Transportation, Federal Highway Administration. pp. 2-6.

2. Cho Y.S., Lin F.B. (2001): Spectral analysis of surface wave response of multi-layer thin cement mortar slab structures with finite thickness. NDT\&E International, 34(2), 115-122. doi:10.1016/S0963-8695(00)00036-0
3. Cho Y.S. (2002): NDT Response of spectral analysis of surface wave method to multi-layer thin high-strength concrete structures. Ultrasonics, 40, 227-230. doi:10.1016/ S0041-624X(02)00142-7

4. Kim D.S., Seo W.S., Lee K.M. (2006): IE-SASW method for nondestructive evaluation of concrete structure. NDT\&E International, 39(2), 143-154. doi:10.1016/j. ndteint. 2005.06.009

5. Kumar J., Hazra S. (2014): Effect of input source energy on SASW evaluation of cement concrete pavement. $A S C E$ Journal of Materials in Civil Engineering, 26(6), 1-7. doi:10.1061/(ASCE)MT.1943-5533.0000827

6. ASTM C666/C666M-15 (2015). Standard test method for resistance of concrete to rapid freezing and thawing. doi: 10.1520/C0666_C0666M-15

7. ASTM C215-14 (2014). Standard test method for fundamental transverse, longitudinal, and torsional resonant frequencies of concrete specimens. doi:10.1520/C0215-14

8. Neville A.M. (2012) Properties of concrete. $5^{\text {th }}$ ed. Prentice Hall.

9. Lu X.B., Sun Q.C., Feng W., Tian J.T. (2013): Evaluation of dynamic modulus of elasticity of concrete using impactecho method. Construction and Building Materials, 47(10), 231-239. doi:10.1016/j.conbuildmat.2013.04.043

10. Lu X.B., Ma F.L., Luke A., Wang R.L. (2015): Assessing frost resistance of concrete by impact-echo method. Magazine of Concrete Research, 67(6), 317-324. doi:10.1680/ macr.14.00051

11. Sansalone M., Streett W. (1997). Impact-echo. Bullbrier Press.

12. Liang M.T., Su P.J. (2001): Detection of corrosion damage of rebar in concrete using impact-echo method. Cement and Concrete Research, 31(10), 1427-1436. doi:10.1016/ S0008-8846(01)00569-5

13. Sansalone M. (1997): Impact-echo: the complete story. $A C I$ Structural Journal, 94(6), 777-786. 